\title{
Stability of insecticide resistance due to amplification of esterase genes in Culex pipiens
}

\author{
MICHEL RAYMOND, ELIE POULIN, VERONIQUE BOIROUX, EDITH DUPONT \& \\ NICOLE PASTEUR \\ Institut des Sciences de l'Evolution (CNRS, URA 327), Laboratoire de Génétique et Environnement, Université de \\ Montpellier I/ (Case courrier 64), 34095 Montpellier 05, France
}

\begin{abstract}
The stability of OP resistance due to amplification of esterase B1 or B2 was investigated in unselected strains. We show that resistance and amplification are both lost when strains are not homozygous for the presence of the amplified genes, due probably to fitness differences. In homozygous strains, both esterases remained amplified and expressed, and resistance was stable during at least 60 generations, indicating that events generating lower gene copy number are uncommon. Results are discussed with respect to the evolution of insecticide resistance.
\end{abstract}

Keywords: amplification, Culex pipiens, fitness cost, mosquito, overproduced esterase.

\section{Introduction}

Overproduction of esterases, due to gene amplification, confers resistance to organophosphorus insecticides (OP) in Culex pipiens mosquitoes (Mouchès et al., 1986; Raymond et al., 1989) and in Myzus persicae aphids (Field et al., 1988). In M. persicae, expression of the amplified gene is lost when insects are reared in the absence of insecticide (ffrench-Constant et al., 1988), and resistance to OPs disappears while amplification remains (Field et al., 1989). In C. pipiens loss of OP resistance has been observed in unselected strains containing the amplified esterase B1 (Georghiou et al., 1983), but molecular studies were not then possible and the nature of this loss could not be investigated.

In the present paper, we have analysed the stability of OP resistance due to amplification of esterase B1 and esterase B2 genes in unselected Culex pipiens strains, and studied the fitness cost of esterase B1 using strains with similar genetic background.

\section{Materials and methods}

Three strains of Culex pipiens derived from Californian populations were used: Tem-R (Georghiou et al., 1980 ), which is OP resistant due to esterase B1 gene amplification (Mouchès et al., 1986), SeLax, which is OP resistant due to esterase B2 gene amplification

Correspondence: Dr N. Pasteur.
(Raymond et al., 1989; Wirth et al., 1990), and S-Lab (Georghiou et al., 1966), which is susceptible to insecticides and possesses a non-amplified esterase B gene. Tem- $R$ and SeLax strains, which are maintained by exposing the fourth-instar larvae of each generation to temephos doses producing a 50-70 per cent mortality, were used to derive a number of other strains.

Tem-R87 and Tem-R88 strains were produced from Tem-R in 1987 and 1988, respectively, by rearing larvae in the absence of temephos.

Tem-R87 was reared with non-overlapping generations during the first 10 generations, and then reared with overlapping generations under conditions of high larval density. In 1990, insects with high esterase activity (i.e. with an amplified esterase $\mathrm{B} 1$ gene) were eliminated by keeping only the progeny of single pair crosses from parents lacking esterase B1. This new strain was named Tem-S.

Tem-R88 was made homozygous for the presence of esterase B1 as follows. Single pair crosses of Tem-R were set up $\left(F_{0}\right)$, and their progeny $\left(F_{1}\right)$ were allowed to inbreed to produce substrains. The presence of esterase B1 in the homozygous state in each substrain was confirmed by crossing $15 F_{1}$ females with S-Lab males, and verifying that the offspring (15 tested) possessed esterase $\mathrm{B} 1$. The probability that one $\mathrm{F}_{0}$ parent was heterozygous for the presence of esterase B1 is therefore lower than $3 \times 10^{-4}$. Tem-R88 was derived from such a substrain and has been maintained in the absence of temephos selection. 
The SeLax 88 strain was derived from SeLax, which is homozygous for the presence of A2-B2 (Wirth et al., 1990 ), by interrupting temephos selection in 1988.

Resistance to temephos was studied by bioassays (at $23 \pm 1^{\circ} \mathrm{C}$ ) according to Georghiou et al. (1966) using either wax cups (for all bioassays in Fig. 1) or plastic cups (for all bioassays in Table 1 and Fig. 2), and mortality data were analysed using the IBM version of the log-probit program of Raymond (1985) based on Finney (1971). Mortality lines were considered

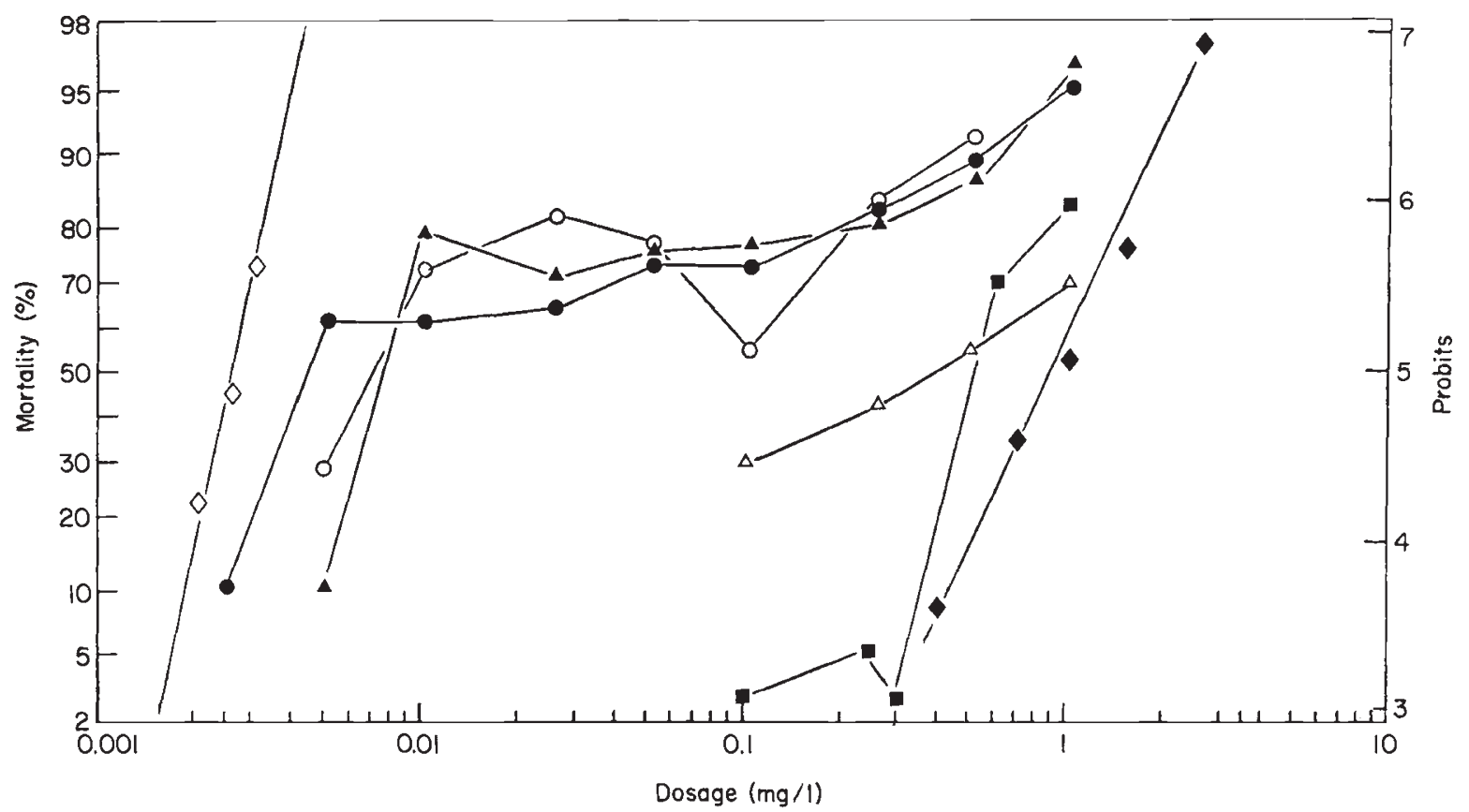

Fig. 1 Evolution of log-probit resistance curves upon relaxation of temephos selection in Tem-R87 strain. Tem-R87 strain or generation $0(\bullet)$, generation no. $4(\bullet)$, generation no. $7(\Delta)$, generation no. $8(\bullet)$, generation no. $9(\Delta)$, generation no. $10(0)$, S-Lab reference strain $(\diamond)$.

Table 1 Temephos resistance observed in S-Lab, Tem-R88, Tem-S, SeLax and SeLax88 strains. Under each strain is noted the year of test. The resistance ratio was computed using the susceptible strain tested the same year

\begin{tabular}{|c|c|c|c|c|c|}
\hline $\begin{array}{l}\text { Strains } \\
\text { (year) }\end{array}$ & $\begin{array}{l}\mathrm{LC}_{50}(\mathrm{mg} / \mathrm{l}) \\
\text { (range) }\end{array}$ & $\begin{array}{l}\mathrm{LC}_{95}(\mathrm{mg} / \mathrm{l}) \\
\text { (range) }\end{array}$ & $\begin{array}{l}\text { Slope } \\
\text { (S.E.) }\end{array}$ & Heterogeneity & $\begin{array}{l}\text { Resistance } \\
\text { ratio at } L_{50}\end{array}$ \\
\hline $\begin{array}{l}\text { S-Lab } \\
(1990)\end{array}$ & $\begin{array}{l}0.0019 \\
(0.0018-0.0021)\end{array}$ & $\begin{array}{l}0.0038 \\
(0.0033-0.0045)\end{array}$ & $\begin{array}{c}5.49 \\
(0.49)\end{array}$ & 1 & 1 \\
\hline $\begin{array}{l}\text { S-Lab } \\
(1991)\end{array}$ & $\begin{array}{l}0.0024 \\
(0.0023-0.0026)\end{array}$ & $\begin{array}{l}0.0047 \\
(0.0042-0.0056)\end{array}$ & $\begin{array}{c}5.61 \\
(0.51)\end{array}$ & 1 & $1.27^{*}$ \\
\hline $\begin{array}{l}\text { Tem-S } \\
(1990)\end{array}$ & $\begin{array}{l}0.0022 \\
(0.0020-0.0023)\end{array}$ & $\begin{array}{l}0.0042 \\
(0.0037-0.0048)\end{array}$ & $\begin{array}{c}5.80 \\
(0.55)\end{array}$ & 1 & 1.16 \\
\hline $\begin{array}{l}\text { Tem-R88 } \\
(1990)\end{array}$ & $\begin{array}{l}2.43 \\
(2.21-2.66)\end{array}$ & $\begin{array}{l}6.94 \\
(5.89-8.64)\end{array}$ & $\begin{array}{c}3.61 \\
(0.30)\end{array}$ & 1 & 1280 \\
\hline $\begin{array}{l}\text { Tem-R88 } \\
\text { (1991) }\end{array}$ & $\begin{array}{l}1.63 \\
(1.56-1.17)\end{array}$ & $\begin{array}{l}2.87 \\
(2.66-3.16)\end{array}$ & $\begin{array}{c}6.69 \\
(0.42)\end{array}$ & 1 & 674 \\
\hline $\begin{array}{l}\text { SeLax } \\
(1990)\end{array}$ & $0.08 \dagger$ & $0.6 \dagger$ & - & - & 40 \\
\hline $\begin{array}{l}\text { SeLax } 88 \\
(1990)\end{array}$ & $\begin{array}{l}0.061 \\
(0.058-0.065)\end{array}$ & $\begin{array}{l}0.139 \\
(0.124-0.161)\end{array}$ & $\begin{array}{c}4.64 \\
(0.35)\end{array}$ & 1 & 32 \\
\hline $\begin{array}{l}\text { SeLax } 88 \\
(1991)\end{array}$ & $\begin{array}{l}0.046 \\
(0.040-0.053)\end{array}$ & $\begin{array}{l}0.076 \\
(0.056-0.105)\end{array}$ & $\begin{array}{c}7.47 \\
(1.19)\end{array}$ & 4 & 19 \\
\hline
\end{tabular}

*Relative to S-Lab tested in 1990. †Calculated from the mortality curve (Fig. 2). 


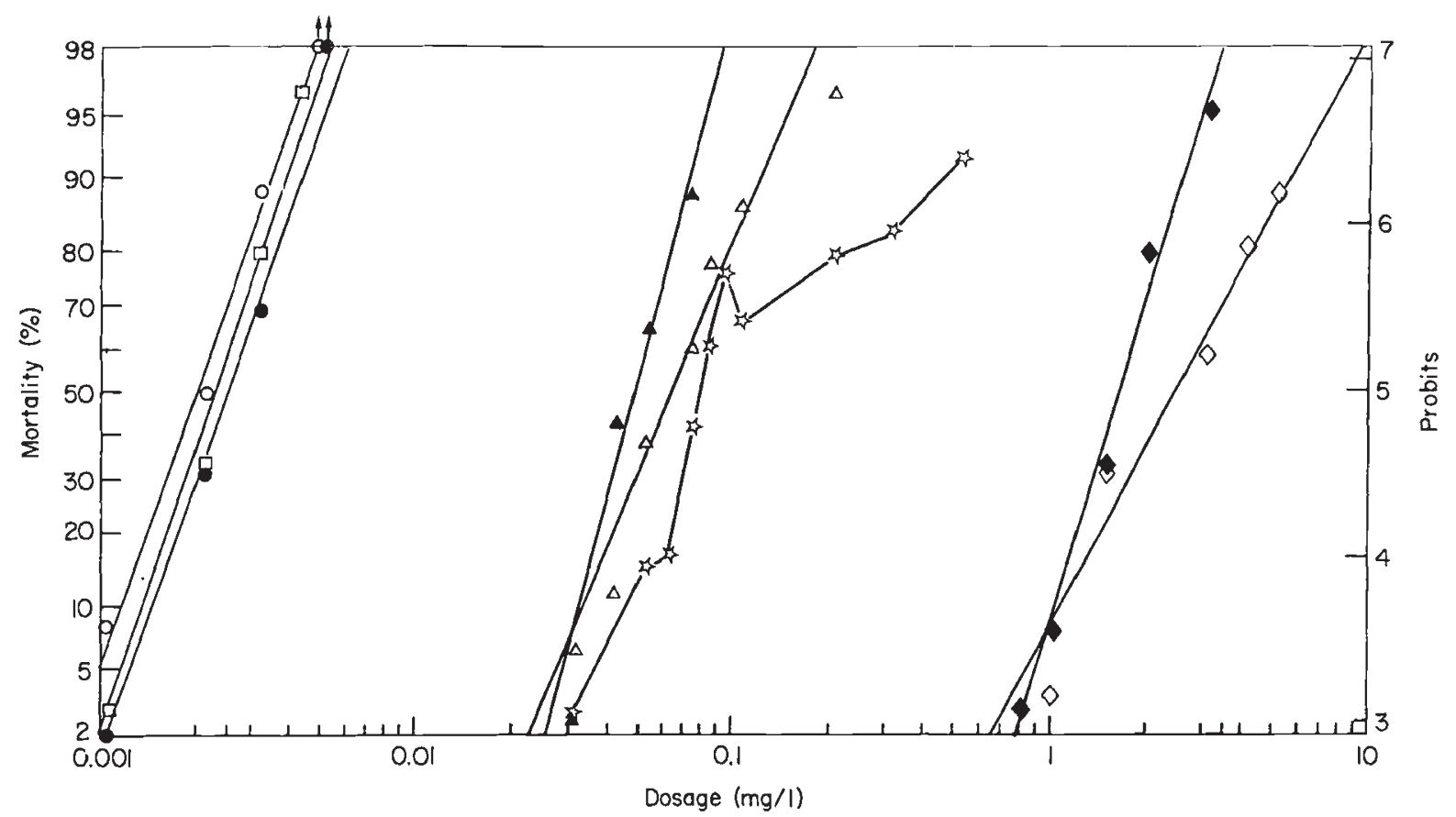

Fig. 2 Mortality curves of various strains tested in 1990 (closed signs) or 1991 (open signs): S-Lab ( and O), SeLax ( $)$ ), $\operatorname{SeLax} 88(\Delta$ and $\Delta)$, Tem-R88 $(\diamond$ and $\diamond)$ and Tem-S $(\square)$.

identical if their parallelism was not rejected at the 5 per cent probability level, and if the confidence limits (at $P>0.05$ ) of the resistance ratio include the value 1 .

The presence or absence of the highly active esterases B1 or B2 was determined in single larvae or adults by starch gel electrophoresis (Pasteur et al., 1988 ) or by the filter paper test of Pasteur \& Georghiou (1989).

Genomic DNA was extracted from pools of 100 adults of the various strains using a phenol/chloroform method (Raymond et al., 1989). DNA was digested in an appropriate buffer with one or two of the following endonucleases: EcoRI, HindIII, XbaI, BamHI, BclI, and $E c o$ RV. The restriction fragments obtained were electrophoresed in 0.8 per cent agarose gels, denatured, neutralized and capillary-blotted onto nylon membranes. Membranes were prehybridized, hybridized overnight with a ${ }^{32} \mathrm{P}$-labelled $1.3 \mathrm{~kb}$ cDNA probe of esterase B1 gene (Mouchès et al., 1990), and washed at high stringency following the method of Maniatis et al. (1982). Filters were autoradiographed with Kodak films at $-80^{\circ} \mathrm{C}$, using an intensifying screen.

The relative fitness of mosquitoes possessing and lacking esterase B1 was analysed on the offspring of two crosses (cross $\mathrm{A}=[\mathrm{Tem}-\mathrm{R} 88 \times \mathrm{Tem}-\mathrm{S}$ ] females $\times$ Tem-S males; cross $B=[$ Tem-R $88 \times$ Tem-S $]$ females $\times[$ Tem-R88 $\times$ Tem-S $]$ males). The progeny of cross A were reared in containers seeded with one (containers I and II, holding $800 \mathrm{ml}$ of water), five (contain- ers III and IV, holding $800 \mathrm{ml}$ of water), and 15 (container V, holding 31 of water) egg rafts; the progeny of cross $B$ were reared in a container (container VI, holding 31 of water) seeded with 35 egg rafts. Pupae were collected every day and each day's collection was placed in a separate cage. The presence or absence of esterase B1 was determined on adults emerging from each cage. The independence of larval development, and the presence or absence of esterase B1 were tested using a $\chi^{2}$ contingency table. Fisher's method (Fisher, 1970; in Manly, 1985) was used to combine the test results of containers I to V. Preadult survival, as seen by deviation from expected values, was compared between mosquitoes with or without esterase B1.

\section{Results}

\section{Evolution of resistance due to esterase B1 gene amplification}

The resistance of Tem-R87 mosquitoes reared in the absence of temephos selection decreased rapidly (Fig. 1). The mortality curve, which was a straight line at generation 0 , displayed a clear plateau around 70 per cent mortality at generations 8-10. After 3 years of insecticide-free rearing (i.e. about 60 generations), the Tem-R87 strain contained 10 per cent of mosquitoes with high esterase activity in a sample of 365 adults but none with intermediate activity. A strain lacking high 
esterase activity, Tem-S, was isolated from Tem-R87 and compared to the reference susceptible strain S-Lab. Temephos resistance (Table 1) was slightly (and significantly, $P<0.05$ ) higher in Tem-S than in S-Lab (resistance ratio $=1.16$ ). Activity and electrophoretic mobility of esterase B were identical in the two strains, but different from Tem-R esterase B1. Similarly, genomic DNA of Tem-S and S-Lab mosquitoes digested with the six endonucleases tested and hybridized with the $1.3 \mathrm{~kb}$ cDNA probe of esterase B1 was identical in size and in the weak strength of the signal, and different in size and signal intensity from Tem- $R$ DNA (results not shown). Tem-S and S-Lab apparently possess the same restriction map at the esterase B region, which is different (Raymond et al., 1991) from the Tem-R map of the same DNA area.

The evolution of resistance in the absence of temephos selection was very different in the Tem-R88 strain, which was homozygous for the presence of the highly active esterase B1. All mosquitoes displayed a high esterase activity in May 1990 as well as in October 1991, i.e. after 40 and 60 generations of rearing in the absence of temephos selection, respectively. The amplification level of the esterase B1 gene, tested in late 1990 , was at least 250 -fold, as previously observed (Mouchès et al., 1986; Raymond et al., 1989). The resistance to temephos at the $\mathrm{LC}_{50}$ was 1280-fold in May 1990 and 674-fold in October 1991 (Table 1), compared to the susceptible reference strain
S-Lab tested alongside; in both cases, log-probit mortality curves were linear but they were not parallel $\left(\chi^{2}=39.1\right.$, d.f. $\left.=5, P<0.001\right)$ and the line was steeper in 1991 (Table 1, Fig. 2), indicating a greater homogeneity among mosquitoes than in 1990 .

As resistance and esterase B1 amplification levels remained high in the Tem-R88 strain homozygous for the presence of esterase $\mathrm{B} 1$, it is likely that resistance was lost in Tem-R87 mosquitoes because the parental strain was not homozygous for the amplified esterase B1. This implies that, in the absence of temephos exposure, the fitness of insects with an amplified esterase B1 is lower than the fitness of insects lacking this amplification.

This hypothesis was tested by comparing the length of larval development (details not shown) and preadult mortality under different conditions of larval density among the offspring of cross A and cross B (Table 2), i.e. among insects of the same genetic background and possessing an amplified esterase B1 (B1/0 genotype in cross $\mathrm{A}$, and $B 1 / B 1$ or $B 1 / 0$ genotypes in cross $\mathrm{B})$, and lacking this amplification (0/0 genotype).

The length of larval development and the presence of esterase B1 in cross A displayed a significant nonindependence for two experiments (i.e. containers no. II and no. V). A combination of the five independent tests (containers nos $\mathrm{I}-\mathrm{V}$ ) gave a significant result with a two-sided test when considering both sexes together $\left(\chi^{2}=20.9\right.$, d.f. $\left.=10, P<0.05\right)$, suggesting a slight but

Table 2 Observed phenotypes in the offspring of cross A ([Tem-R $88 \times$ Tem-S] $\times$ Tem-S $)$ and cross $B([$ Tem-R $88 \times$ Tem-S $] \times[$ Tem-R $88 \times$ Tem-S $])$, reared under different conditions of larval density

\begin{tabular}{|c|c|c|c|c|c|c|}
\hline \multirow[b]{2}{*}{ Cross } & \multicolumn{2}{|l|}{ Male } & \multicolumn{2}{|l|}{ Female } & \multicolumn{2}{|l|}{ Total } \\
\hline & With B & 11 Without B1 & With B1 & Without B1 & With B1 & Without B1 \\
\hline \multicolumn{7}{|l|}{ Cross A } \\
\hline I & 52 & 40 & 55 & 40 & 107 & 80 \\
\hline II & 38 & 47 & 52 & 51 & 90 & 98 \\
\hline III & 88 & 93 & 117 & 99 & 205 & 192 \\
\hline IV & 206 & 197 & 140 & 121 & 346 & 319 \\
\hline V & 315 & $* * \quad 242$ & 112 & 121 & 427 & 363 \\
\hline Total & 699 & * 619 & 476 & 433 & $1175 *$ & ** 1052 \\
\hline \multicolumn{7}{|l|}{ Cross B } \\
\hline VI & $\begin{array}{c}623 \\
(747)\end{array}$ & $\begin{array}{r}* * * *=373 \\
(249)\end{array}$ & $\begin{array}{l}422 \\
(539)\end{array}$ & $\begin{array}{c}277 \\
(180)\end{array}$ & $\begin{array}{l}1065 \\
(1286)\end{array}$ & $\begin{array}{cc}6 * * & 650 \\
& (429)\end{array}$ \\
\hline
\end{tabular}

Bold or bold italic characters indicate a significant $(P<0.05)$ non-independence between phenotypes and time of pupation; italic refers to a two-sided combination of the five (containers I-V) independent tests (see text). Stars indicate a significant $(P<0.05$ for $*, P<0.01$ for ** and $P<0.001$ for $* *)$ departure for the $1: 1(\operatorname{cross} \mathrm{A})$ or 3:1 (cross B) segregation ratio. Expected numbers for cross $B$ are indicated in parentheses. 
general trend of dependence between the tested variables. When males alone were considered, only one container (no. IV) provided a significant result $(P<0.05)$, but again the combination of the five independent experiments gave a significant result on a twosided test $\left(\chi^{2}=21.2\right.$, d.f. $\left.=10, P<0.05\right)$. This was not true when females alone were considered: none of the containers of cross A gave a significant result independently or in combination $\left(\chi^{2}=9.78\right.$, d.f. $=10$, $P>0.1$ ).

In cross $\mathrm{B}$, three different genotypes exist $(B 1 / B 1$, $B 1 / 0$ and $0 / 0$ ), but only two phenotypes are identified, one with at least one $B I$ chromosome and the other with none. The non-independence between the presence of $B 1$ and development time was significant in females $(P<0.02)$, but not in males.

Thus in neither cross was there a tendency for development time to increase or decrease systematically, so that its exact interpretation in fitness terms needs further consideration.

Preadult mortality was significantly $(P<0.0001)$ larger in insects with esterase $B 1$ than in insects lacking this enzyme for cross B, i.e. under rearing conditions of high larval density (container no. VI, seeded with 35 egg rafts, which produced a mean of 49 adults/egg raft, compared to 187 or 188 adults/egg raft for containers nos I or II) and with three different competing genotypes $(B 1 / B 1, B 1 / 0$ and $0 / 0)$. In contrast, preadult mortality was significantly larger for $0 / 0$ genotypes competing with $B 1 / 0$ mosquitoes in cross A (Sign test, five comparisons for males and five for females, seven with a higher number of mosquitoes with $\mathrm{B} 1, P<0.06$ ). This general tendency was significant for containers no. $\mathrm{I}(P<0.05)$ and no. $\mathrm{V}(P<0.03)$. The addition of the five independent experiments resulted in a highly significant $(P<0.01)$ preadult mortality of $0 / 0$ genotypes as compared to $B 1 / 0$ genotypes (Table 2 ).

\section{Evolution of resistance due to esterase $B 2$ gene amplification}

All mosquitoes of SeLax88 (maintained in absence of selection) and SeLax (selected each generation with temephos) strains displayed an esterase B2 with a comparable activity when analysed by starch gel electrophoresis in May 1990. Similarly, the genomic region hybridizing with the $1.3 \mathrm{~kb} \mathrm{cDNA}$ probe of esterase B1, disclosed a signal of similar intensity, and fragments with identical sizes in both strains with the six restriction enzymes used (data not shown).

Temephos resistance was tested in May 1990 on SeLax and SeLax88, and repeated on SeLax88 in October 1991 (Table 1). The dose mortality curves of SeLax88, tested in 1990 and 1991, were linear and statistically identical, i.e. the parallelism was not rejected $\left(\chi^{2}=9.60,6\right.$ d.f., $\left.P>0.05\right)$ and their confidence limits at the 5 per cent level (0.99-3.81) included the value 1 , although this was not true at the 4 per cent level. It is safe to consider that resistance in SeLax 88 has slightly decreased from 1990 to 1991 , and that the slope has become steeper (from 4.64 in 1990 to 7.47 in 1991, Table 1) although this slope increase was not significant. In contrast, the mortality curve of SeLax (tested in 1990) displayed a clear plateau around 80 per cent mortality (Fig. 2), indicating the presence of two subpopulations $\left(S_{1}\right.$ and $\left.S_{2}\right)$ with different resistance levels. Mosquitoes with the most efficient resistance mechanism observed in SeLax $\left(S_{2}\right)$ were either lost in SeLax88 upon relaxation of temephos selection, or their frequency increased in SeLax after the onset of temephos selection.

The relative resistance stability observed in SeLax 88 over a period of 3 years indicates that neither resistance nor expression of amplified esterase B2 were lost by interrupting temephos selection.

\section{Discussion}

\section{The stability of esterase amplification}

Our results have shown that esterase gene amplification for both B1 and B2 is stable for at least 3 years, i.e. about 60 generations, when insecticide selection is relaxed. The slight decrease in resistance in both TemR88 and SeLax88 between 1990 and 1991 suggests that the two strains contained insects with 'alleles' corresponding to amplifications with slightly different numbers of esterase $B$ gene copies, and that only highly amplified alleles were lost. First, the slopes of mortality lines were steeper in 1991 than in 1990, indicating a higher homogeneity of the strains for temephos resistance. Second, the levels of lower resistance for each strain were similar in 1990 and 1991 (i.e. the LCs at a low mortality are the same), suggesting that alleles more susceptible (i.e. less amplified) than the ones already existing have not been generated. The loss of highly amplified alleles could be explained by their fitness cost relative to less amplified alleles (see below).

Thus, the previously described appearance of insects lacking esterase B1 upon selection relaxation (Georghiou et al., 1983) was probably not due to the loss of expression of amplified esterase B (see below) but rather to the selection of non-amplified alleles that were still present at low frequency in the strain: this 'instability' apparently disappeared when Tem-R strain was made homozygous for amplified alleles.

The fact that alleles more susceptible (i.e. less amplified) than the ones already existing have not occurred 
during at least 60 generations indicates that events generating lower copy number, such as unequal crossing over, are uncommon. It is not known whether this inability to go backward in gene copy number is circumstantial (i.e. that by chance the phenomenon has not occurred in these strains during the length of time studied), or whether it is a fundamental property of these amplifications due to the type of amplicon organization or to peculiarities of the molecular system responsible for their existence. In the first situation an isolated homozygous resistant population could generate less amplified and even susceptible (i.e. one gene copy per chromosome) individuals when insecticide selection is interrupted. In the second case, less amplified or susceptible individuals can only occur through migration from a less resistant population. Evolution of amplification in natural populations (which could be organized as metapopulations) will be different depending on these two possibilities.

\section{Expression of gene amplification}

It is already known that B1 gene amplification is present in all the life stages of the Tem-R strain and in the haploid phase (Nancé et al., 1990; Raymond \& Pasteur, 1989), which suggests that amplification is constitutive. The esterases B1 or B2 are overproduced from the first larval instar until adulthood, indicating that no regulation in time is operating. However, we do know that tissue specific expression occurs (Nancé, 1991).

Our results have revealed that both esterase B1 and B2 amplified genes remain expressed in mosquitoes 3 years after complete removal of known insecticide selection. This situation differs greatly from that of $M y$ zus persicae in which the expression of the amplified esterase genes conferring organophosphate resistance is lost after a few generations in the absence of insecticide exposure (Devonshire \& Field, 1991). This apparent inability of Culex mosquitoes to regulate the expression of their amplified esterase genes according to environmental signals indicates that further selection to tune the system might be possible.

Thus, in contrast to Myzus persicae, the resistance of natural populations of Culex pipiens is easier to monitor as they do not contain susceptible insects with an amplification which could be reactivated and lead rapidly to a high resistance, when exposed to OP control.

\section{Fitness cost of esterase amplification}

Two components of fitness cost associated with esterase B1 have been estimated: the length of larval development and preadult mortality. Both give results indicating a complex relationship between esterase B1 and fitness cost.

The non-independence between development time and esterase B1 was significant in two experiments (cross A, container nos II and V) out of six when both sexes were considered, and in two other experiments when the analysis was performed on males (cross A, container no. IV) or females (cross B) alone. This indicates that the fitness difference is slight and may vary with sex and some environmental parameters. Combination tests were generally significant, supporting the idea of a slight but general effect associated with the presence of esterase B1. This effect was not a tendency to increase or decrease development time systematically, so that its exact interpretation in fitness terms needs further consideration.

Preadult mortality was significant in three experiments (cross A, containers I and V; cross B, container VI), but opposite and significant results were found for the two crosses: mosquitoes lacking esterase B1 survived better in cross B and less in cross A. Two explanations are possible. First, the competing genotypes were not the same in the two crosses $(B I / 0$ and $0 / 0$ for cross A, BI/BI, BI/0 and $0 / 0$ for cross B) and had different frequencies. Secondly, the larval density was much higher in cross $\mathrm{B}$ than in cross $\mathrm{A}$, and it is known that this parameter may exacerbate fitness differences (e.g. Reboud \& Till-Bottraud, 1991).

In conclusion, there is an effect of esterase B1 on fitness in an environment free of insecticide but the direction and strength of this effect seems variable according to several interacting parameters among which frequencies of genotypes, sex and larval density may contribute. It is not excluded that under other environmental conditions, such as those prevailing in natural populations, other parameters are pivotal to estimate cost associated with esterase amplification.

The effect on fitness of phenotypes carrying an amplified esterase B gene, relative to phenotypes lacking such an amplification, in the absence of insecticide, was clearly demonstrated for the first time, as previous studies (Ferrari \& Georghiou, 1981; El-Khatib \& Georghiou, 1985) were performed on strains with different genetic backgrounds.

\section{Acknowledgements}

This study was supported by the Ministère de l'Education Nationale (grant No. 89. 1540), the Ministère de la Recherche et de la Technologie (grant No. 91.C.0939), and the Programme Environnement from CNRS. We would like to thank M. Marquine for technical assistance, E. Marboutin for help in reversion studies, E. 
Nancé for making the Tem-R88 strain available and an anonymous reviewer for valuable criticism on the fitness data.

\section{References}

DEVONSHIRE, A. L. AND FIELD, L. M. 1991. Gene amplification and insecticide resistance. Ann. Rev. Entomol, 36, 1-23.

EL-KHATIB, Z. AND GEORGHIOU, G. P. 1985. Comparative fitness of temephos-resistant, -susceptible, and hybrid phenotypes of the southern house mosquito (Diptera: Culicidae). J. Econ. Entomol., 78, 1023-1029.

FFRENCH-CONSTANT, R. H., DEVONSHIRE, A. L. AND WHITE, R. P. 1988. Spontaneous loss and reselection of resistance in extremely resistant Myzus persicae (Sulzer). Pest. Biochem. Physiol., 30, 1-10.

FIELD, L. M., DEVONSHIRE, A. L. AND FFRENCH-CONSTANT, R. H. 1989. Changes in DNA methylation are associated with loss of insecticide resistance in the peach-potato aphid Myzus persicae (Sulz.). FEBS Let., 243, 323-327.

FIELD, L. M., DEVONSHIRE, A. L. AND FORDE, B. G. 1988. Molecular evidence that insecticide resistance in peach-potato aphids Myzus persicae Sulz. results from amplification of an esterase gene. Biochem. J., 251, 309-312.

FINNEY, D. J. 1971. Probit Analysis. Cambridge University Press, Cambridge.

FERRARI, J. A. AND GEORGHIOU, G. P. 1981. Effects of insecticidal selection and treatment on reproductive potential of resistant, susceptible, and heterozygous strains of the southern house mosquito. J. Econ. Entomol., 74, 323-327.

GEORGHIOU, G. P., LAGUNES, A. AND BAKER, J. D. 1983. Effect of insecticide rotations on evolution of resistance. In: Miyamoto, J. (ed.), Human Welfare and the Environment, IUPAC Pesticide Chemistry, Pergamon Press, New York, pp. 183-189.

GEORGHIOU, G. P., METCALF, R. L. AND GIDDEN, F. E. 1966. Carbamate resistance in mosquitoes: selection of Culex pipiens fatigans Wied. (=Culex quinquefasciatus) for resistance to Baygon. Bull. WHO, 35, 691-708.

GEORGHIOU, G. P., PASTEUR, N. AND HAWLEY, M. K. 1980. Linkage relationships between organophosphate resistance and a highly active esterase B in Culex pipiens quinquefasciatus Say from California. J. Econ. Entomol., 73, 301-305.

MANIATIS, T., FRITSCH, E. F. AND SAMBROoK, J. 1982. Molecular Cloning: A Laboratory Manual. Cold Spring Harbor Laboratory, New York.

MANLY, B. J. F. 1985. The Statistics of Natural Selection. Chapman \& Hall, London.
MOUCHES, C., PASTEUR, N., BERGE, J. B., HYRIEN, O., RAYMOND, M., ROBERT DE SAINT VINCENT, B., DE SILVESTRI, M. AND GEORGHIOU, G. P. 1986. Amplification of an esterase gene is responsible for insecticide resistance in a California Culex mosquito. Science, 233, 778-780.

MOUCHES, C., PAUPLin, Y., AGARWAL, M., LemieUX, L., HERZOG, M., ABADON, M., BEYSSAT-ARNAOUTY, V., HYRIEN, O., ROBERT DE SAINT VINCENT, B., GEORGHIOU, G. P. AND PASTEUR, N. 1990. Characterization of amplification core and esterase B1 gene responsible for insecticide resistance in Culex. Proc. Natl. Acad. Sci., U.S.A., 87, 2574-2578.

NANCE, E. 1991. Localisation chromosomique et expression tissulaire des gènes amplifiés codant les estérases impliquées dans la résistance aux insecticides organophosphorés chez Culex pipiens. Thèse de Doctorat, Université de Montpellier II.

NANCE, E., HEYSE, D., BRITTON-DAVIDIAN, J. AND PASTEUR, N. 1990. Chromosomal organization of the amplified esterase B1 gene in organophosphate-resistant Culex pipiens quinquefasciatus Say (Diptera, Culicidae). Genome, 33, 148-152.

PASTEUR, N. AND GEORGHIOU, G. P. 1989. Improved filter paper test for detecting and quantifying increased esterase activity in organophosphate-resistant mosquitoes (Diptera: Culicidae). J. Econ. Entomol., 82, 347-353.

PASTEUR, N., PASTEUR, G., CATALAN, J., BONHOMME, F. AND BRITTONDAvidian, J. 1988. Practical Isozyme Genetics. Ellis Horwood Ltd, Chichester, England.

RAYMOND, M. 1985. Présentation d'un programme 'Basic' d'analyse log-probit pour micro-ordinateur. Cah. ORSTOM sér. Entomol. Méd. Parasitol., 23, 117-121.

RAYMOND, M., BEYSSAT-ARNAOUTY, V., SIVASUBRAMANIAN, N., MOUCHES, C., GEORGHIOU, G. P. AND PASTEUR, N. 1989. Diversity of the amplification of various esterases $B$ responsible for organophosphate resistance in Culex mosquitoes. Biochem. Genet., 27, 417-423.

RAYMOND, M., CAllaghan, A., FORT, P. AND PASTEUR, N. 1991. Worldwide migration of amplified insecticide resistance genes in mosquitoes. Nature, 350, 151-153.

RAYMOND, M. AND PASTEUR, N. 1989. The amplification of B1 esterase gene in the mosquito Culex pipiens is present in gametes. NAR, 17, 7116.

REBOUD, X. AND TILL-BOTTRAUD, I. 1991. The cost of herbicide resistance measured by a competition experiment. Theor. Appl. Genet., 82, 690-696.

WIRTH, M. C., MARQuine, M., GEORGHIOU, G. P. AND PASTEUR, N. 1990. Esterases A2 and B2 in Culex quinquefasciatus (Diptera: Culicidae): role in organophosphate resistance and linkage studies. J. Med. Entomol., 27, 202-206. 